\title{
The Development Paths of Social Welfare Networks in Italy from Integration to Cooperation
}

\author{
Maria Carmen Agnello* \\ Specialist in Health law, University of Bologna, Bologna, Italy
}

Corresponding to: Maria Carmen Agnello, Specialist in Health law, University of Bologna, Bologna, Italy.

Received date: April 7, 2021; Accepted date: April 19, 2021; Published date: April 26, 2021

Citation: Agnello MC (2021) The Development Paths of Social Welfare Networks in Italy from Integration to cooperation. J Med Res Surg 2(2): pp. 1-2. doi: $10.52916 / j m r s 214045$

Copyright: (C) 2021 Agnello MC. This is an open-access article distributed under the terms of the Creative Commons Attribution License, which permits unrestricted use, distribution, and reproduction in any medium, provided the original author and source are credited.

The reorganization of hospital and territorial services: non-auto sufficiency and "functional limitations". The increase social welfare

in aging and chronic degenerative diseases implies reorganizing

The Italian health system is extended to social welfare benefits the Hub and Spoke model towards the implementation of long provided in the face of needs related to diseases that lead to term care and home care.

Table 1: Population forecasts from 2019 to 2066.

\begin{tabular}{|l|l|l|l|}
\hline Pouplation & 2019 & 2066 & VAR\% 2019-2066 \\
\hline ITALY & 60380917 & 53513604 & $-11,40 \%$ \\
\hline Source: elaboration on Istat data- CREA -HEATH & \\
\hline
\end{tabular}

At the base of this reorganisation is the need to identify an organizational model integrated with the current territorial care pathways, of which the protected remission model for patients in the post-acute phase.

The network is an organizational model of increasing importance in the Western welfare, able to implement the organizational and professional resources available. However, the management of social networks has previously had uncertain outcomes. in the Italian social-welfare context for the critical issues in defining this model in the policy objectives and management procedures.

The clinical care network is defined in the national health system by D.M. n. 70/2015 that protects the global care of the patient in conditions of appropriateness, effectiveness, efficiency, quality and safety of care, through the relationship between professionals, structures and services that provide health and social health interventions of different types and levels.

The impact of the Covid has been to remodulate the existing paths of assistance and care in order to make them functional in dealing with this emergency. The most urgent projects started were developed through models oriented to integration between hospitals and territory.

Relations between networks and territorial medicine: the implementation of integration

In the National Health System, hospital structures are responsible for dealing only with emergency and acuity. Chronicities cannot be a burden only on hospitals, to avoid congestion. The most recent results demonstrate the improvement of chronic care through the integration between hospital care and postresignation medical care through local capillary services.

In improving this model we need to create a more efficient alternative. The analysis of the networks of social and health services is to focus on the ability to react to epidemological and demographic camabias, as emerged in the most acute phase of the emergency, together with the development of an increasingly personalized medicine. In this context, social welfare networks can respond to the needs of chronicity and fragility, through an approach able to transfer to the territory not only follow-upup but also subsequent care paths that always require a high level of specialization. This implies the implementation of the current set-up of networks for pathology able to support the continuity of care for acute post.

This change in the internal hospital management model implies a greater understanding of assistance on the territory through an effective digitization of the axial processes able to ensure continuity of care at home. On the one hand, we need to move low-burden care to the patient's home, on the other hand, we need to insist on innovation and personalized medicine in order to guarantee not only continuity, but more and more personalised care. This implies an implemtazione level of specialization of intermediate levels of territorial assistance and digitization increasingly oriented to the continuity of care.

The remote health services connected to the Telemedicine, used during the emergency COVID-19, were teleconsultation, teleconsultation, television and other types of video call with control and surveillance function (for people in quarantine without symptoms). The current goal of digitization is to make the user's home the main place for providing social assistance services.

These tools beyond the current emergency are to be implemented ensuring the best level in the relationship between efficient costs and utility costs in terms of reliability and reliance.

\section{The paths of cooperation and coordination: the network of networks and the network of actors}

The Clinical Networks are defined by an institutional table, coordinated by AGENAS, made up of representatives of the Ministry of Health and the Regionals. The objective pursued is to define programming tools such as guidelines and recommendations and update existing ones in order to guarantee concrete implementation through the definition of qualitative, structural, technological and quantitative standards. This planning phase was followed by the agreement in the State-Regions Conference of 24.01.2018 "Guidelines for the revision of clinical networks - Time dependent networks, such as cardiology for emergency, for neonatology and birth points, 
the stroke network, the trauma network.

In this planning framework it is necessary to identify organizational tools capable of concretely implementing the LEAs, through the implementation of the network of territorial services integrated between the hospital and the social assistance system.

Cooperation involves following the following paths in order to ensure the centrality of the patient.

Greater cooperation, both vertical and horizontal, is essential in the management of networks, through the creation of the "network of networks" capable of harmonising current routes and limiting regional mobility. Following the Covid-19 pandemic, projects have been launched at regional level. The first regions that have undertaken this project are Tuscany, Veneto and Campania.

"Networks of actors" means providing coordinated and synergistic responses between social and health services in order to respond to the growing need for benefits.

A best practice is the Cracking Cancer Forum that takes place every year in Italy to develop projects that break the paradigms of cancer care and care. In the first edition in Florence, an attempt was made to create a dialogue on the issues of care in the oncology field in which medical specialists were involved, such as oncologists and researchers, sociologists, communication experts and institutions, representatives of professional associations and citizens, pharmacoeconomists and innovation experts, in the socio-welfare perspective of chronicities. The 10-point manifesto stresses the importance of ensuring care for all, and giving attention to the person, overcoming the specificities of each individual Region, strengthening the networks, as social welfare objectives to pursue.

Recently the Lazio Region and patient associations have started a laboratory on health information systems with infectious disease centers in order to simplify and improve assistance through telemedicine.

\section{The investments to the social and health expenditure}

The social and health expenditure relates to health care in support of people in fragile conditions, the elderly and the disabled.

The current emergency from Covid-19 had the financial impact of requiring the reshaping of the level of funding for the year 2020, per capita with an increase of $€ 23.4$ At regional level were allocated $€ 1.4$ billion. Additional to strengthen territorial assistance, and the purchase of additional healthcare. To these must be added $€ 53.9$ per capita sanctioned by the so-called Decree Relaunch; as a result, for 2020, an average per capita funding of $€ 2,003.1$.

Infine, regarding the planning lines of investment to be realized in the next quinquennium through the resources that will be assigned to Italy from the Recovery Fund, it is to emphasize as these last ones are not destined to "support" current health expenditure only to the extent that it is ancillary to planned multiannual investments. It should also be borne in mind that there is still no "measure" of repayment of these funds: it is certain that they will generate new debt and if, therefore, the planned investments will not be conducive to greater efficiency of the health system as a whole, In the future, they risk undermining the precarious financial equilibrium of our SSN once again.These investments do not guarantee the certainty of achieving results, without planning choices, as imposed with PNRR, through a governance of public expenditure aimed at optimizing the current social welfare model to the network.

The sixth mission of the PNRR for Health has allocated 18.5 million in order to strengthen and guarantee equity in the provision of health services. To this end, the investment in local assistance throughout the territory and provides for the activation of 1,288 community homes and 381 community hospitals and the strengthening of home care to reach 10 percent of the population over 65 , and the implementation of telemedicine and remote assistance, with the activation of 602 Territorial Operations Centers.

\section{References}

1. Integrated care: how difficult it is to replicated an innovative techology- enabled service model, Rossi Mori A., in press, 2021;

2. Effects of Care Coordination on Hospitalization, Quality of Care, and Health Care Expenditures Among Medicare Beneficiaries- Randomized Trials, JAMA 301(6):603-618.

3. COVID-19 - Reflections on the pandemic and the need to review the health system, edited by I. Mastrobuono, FRG Editore 2021;

4. General Accountancy of the State (various years), The Monitoring of health ex-penditure.

5. Istat (various years), Various statistical tables, www.istat.it Ministry of Health (various years), Model of recognition of the Income Statement. 